\title{
El papel de los estudios lingüísticos en la investigación psicosocial: el caso de las pasiones y los sentimientos
}

\author{
Rom Harré \\ Georgetown University
}

\section{Resumen}

Entendiendo la conversación como el modelo principal para comprender los episodios sociales, este trabajo pretende plantear un nuevo paradigma en psicología social y explorar sus aportaciones en la investigación psicosocial. Las destrezas lingüísticas se presentan como el medio a partir del cual se construyen los episodios sociales, y conceptos como acción, acto y posición son planteados como conceptos útiles para entender la vida cotidiana. A continuación se intenta desarrollar la aplicabilidad de dichos conceptos a partir de un ejemplo centrado en las emociones, pasiones y sentimientos, llegando a la conclusión de que este nuevo paradigma en psicología social presenta la oportunidad de vencer aquellos problemas que presenta la psicología de las culturas ajenas o la psicopatología.

Palabras clave: Acción, acto, posición, emociones, pasiones, investigación psicosocial.

\begin{abstract}
Assuming conversation as the principal model for understanding social episodes, this work aims at presenting a new paradigm in social psychology, exploring its contributions to psychosocial research. Linguistic skills are presented as the way through which social episodes are constructed, and notions as action, act and position are plotted as useful notions for the understanding of daily life. Then, the application of these notions takes place through examples of emotions, passions and feelings. The conclusion is that this new paradigm in social psychology offers the opportunity to overcome problems from the psychology of a different culture or psychopathology.
\end{abstract}

Keywords: Action, act, position, emotions, passions, psychosocial research. 


\section{Introducción. Los principios de un nuevo paradigma en Psicología social}

Los fenómenos sociales se dan en una red de interacciones entre dos o más personas. Estas interacciones son dinámicas y tienen una estructura temporal. Por ejemplo, la amistad es una propiedad compleja que acaece en un grupo de seres humanos y que se desarrolla día a día.

Pues bien, las destrezas simbólicas constituyen el medio a partir del que se construyen los episodios sociales. Las más importantes, entre éstas, son las destrezas lingüísticas. La relación entre el ser humano y un episodio social es un buen ejemplo de la relación herramienta-tarea. Las herramientas son símbolos para llevar a cabo tareas sociales.

El modelo principal —en el sentido de qué "modelo" tiene dentro de las ciencias naturales, por ejemplo, analogía o metáfora_ para la Psicología es la conversación. Hay dos versiones de esto: un episodio que es verdaderamente una conversación, y un episodio que se desarrolla como una conversación.

¿Qué pasa cuando se aplica todo esto en la investigación psicosocial?

1. Se explicitan los actos simbólicos de las personas en su entorno social.

2. Se explicitan reglas, convenciones, costumbres y prácticas. Por ejemplo, la elaboración de una amistad en Inglaterra requiere una secuencia de comidas diferente a la que se requiere en otros lugares - un encuentro para tomar dulces es previo al encuentro para tomar una comida formal con platos de carne, etc.

En general, las personas no conocen explícitamente las reglas, normas, etc. que manejan implícitamente. La tarea de los psicólogos sociales consiste en hallar y sacar a la luz esas reglas cotidianas.

3. Se plantean muchos interrogantes para los psicólogos cognitivos, por ejemplo, en qué consiste la estructura de una jerarquía de reglas para realizar un tarea social.

Metodologías para la investigación psicosocial

Para llevar a cabo un programa de investigación empírica en nuestro campo existen dos métodos básicos:

\section{Los métodos directos}

Consisten en realizar registros de los episodios actuales de la vida cotidiana, que es el asunto principal de nuestra disciplina. Un ejemplo es el análisis del gamberrismo en el fútbol inglés. A continuación, se estudian tales acontecimientos conceptualizándolos como "actos" y "reglas". La hipótesis de fondo consiste en que las personas poseen las destrezas suficientes para llevar a cabo el episodio. Debemos prestar especial atención a las explicaciones que realizan los propios implicados en el episodio. Al final, se logra una representación de las condiciones cognitivas que hacen posible este tipo de episodio. 


\section{Los métodos indirectos}

En un estudio indirecto típico los "sujetos" contestan una lista de cuestiones o hacen un comentario sobre dos asuntos:

a. Episodios que se dan en sus propias vidas. Un ejemplo son los estudios de Argyle sobre la felicidad.

b. Relatos, historias de los episodios, pequeñas narraciones. Por ejemplo, los estudios de Crystal sobre la amistad en los jóvenes.

Además, existen dos posibilidades de trabajo: la investigación puede ser extensiva o intensiva.

i. Intensiva: las preguntas a cada uno de los "sujetos" elaboran un tipo de representación.

ii. Extensiva: las preguntas del conjunto total de los "sujetos" investigados son analizadas con métodos estadísticos para delimitar una tendencia central.

Estos métodos ofrecen, sobre todo, una semántica, un vocabulario que las personas utilizan para hablar sobre los temas sociales que aparecen en sus preguntas, y algunas convenciones que se usan para elaborar ciertas narrativas sobre acontecimientos de su vida cotidiana.

\section{Nuevos conceptos (detalles)}

Hay dos grupos de conceptos importantes.

\section{Acciones $y$ actos}

Una acción no es más que el comportamiento que un ser humano realiza con alguna intención. Ésta no es ni un accidente ni un movimiento reflejo regido por un principio de causalidad. Un acto es el sentido que tiene una acción dentro de un entorno social y de acuerdo con las creencias de los actores implicados en éste. La misma acción, planteada en contextos diferentes, tiene sentidos diferenciados. Por tanto, la relación entre una acción, descrita exclusivamente con parámetros físicos, y un acto puede implicar dos o más comportamientos. Por ejemplo, un beso entre dos amigas despliega amistad, pero dentro del jardín de Gethsemane, el beso de Judas fue un acto de traición.

\section{Posición}

Las posibilidades que tiene un individuo de realizar actos en un momento social concreto están restringidas por la distribución de derechos que se da en éste y, sobre todo, por las personas que participan en la interacción. Por ejemplo, los padres de un niño poseen el derecho de golpearlo en función de su comportamiento. Un amigo de la familia no tiene esa clase de derecho, en general. Pero hay otro tipo de posiciones, creadas por una atribución de propiedades psicológicas, por ejemplo: "tonto", "inteligente", "de mente débil", "cambia su mente con demasiada facilidad", etc. Las características mentales son relevantes en las posiciones morales (véase Langenhove \& Harré 1999). Hay tres clases de actos: todos los actos en general; todos los actos que tienen sentido en un entorno social; y todos los actos que son posibles para un individuo en virtud de su posición en un episodio social final. 


\section{Aplicaciones}

La distribución de las posiciones cambia frecuente y rápidamente dentro de un episodio de interacción. Las posiciones no son fijas como lo son los roles. Por ejemplo, el rol de profesor está vinculado a un rol de alumno bajo las reglas de una universidad. Pero es posible que una amistad se desarrolle entre el profesor y su alumno gracias a que comparten una pasión: jugar al ajedrez. La primera relación es claramente un rol, la segunda es una posición.

A menudo hay muchas mini-guerras entre los sexos, que podemos entender usando los conceptos de acto social y posición. La acción que se da depende de las posiciones que ocupan las personas en un episodio social. Cada episodio tiene una gama de posiciones, un río de actos que realizar en su devenir habitual, es como si viviéramos en un "culebrón". Así, el cómo se despliega una emoción es algo público, un acto social, y qué emoción existe en un momento dado depende de las posiciones de los actores en ese momento y, por la misma razón, depende de la historia dramática que desarrolla en dicho episodio.

Las emociones se plantean dentro de un campo complejo. En éste encontramos los sentidos de los acciones como actos, los derechos y obligaciones que se despliegan como acontecimientos y existe el enredo del drama que los actores llevan a cabo en sus acciones. Hay muchos ejemplos de investigaciones llevadas a cabo bajo el nuevo paradigma. Sin embargo, desde mi punto de vista, las más interesantes son las que tienen que ver con las emociones, sentimientos y pasiones. A continuación presentaré el análisis de un ejemplo importante para entender la vida cotidiana.

\section{Las emociones, pasiones y sentimientos}

La primera tarea es desarrollar una taxonomía sistemática que permita hallar las relaciones entre los conceptos que tienen expresión en el idioma natural.

\section{Celos y envidia}

\section{Envidia}

Sean dos muchachos: José y Miguel. José tiene una bicicleta muy buena, con doce cambios de marcha, etc. Y Miguel tiene envidia.

¿Por qué? Las creencias de Miguel incluyen:

José tiene dicha bicicleta.

Yo, Miguel, quiero tener una bicicleta como ésa.

José tiene su bicicleta por derecho, porque trabaja en la tienda de su padre todos los sábados y domingos.

Hay dos versiones de la envidia:

Envidia buena: Miguel no se siente humillado por la buena fortuna de su amigo. Su estrategia consiste en ahorrar dinero para comprarse una bicicleta. 
Envidia mala: Miguel se siente humillado por la situación. Su estrategia consiste en plantear que José no tiene derecho a la bicicleta. Su padre le ha pagado demasiado dinero por el trabajo. Posiblemente Miguel empezará a pensar que una bicicleta no es una cosa lo bastante buena para él, etc.

\section{Celos}

Sean dos hombres: Juan y Pablo. Juan tiene una mujer, Conchita, muy hermosa. Pablo es soltero. Un día Juan observa que su amigo Pablo besa a Conchita. Juan se siente celoso de Pablo.

¿Por qué? Las creencias de Juan incluyen:

a. Juan siente un fuerte amor por Conchita.

b. Ya que Conchita es su esposa, sólo él tiene derecho a besarla.

c. Pablo no tiene ese derecho.

La estrategia de Juan consiste en encerrar a su esposa dentro de casa, cerrar la puerta con llave y traer a su madre como vigilante. O también puede matar a Conchita, en el más puro espíritu de Bodas de Sangre: si él no tiene a Conchita, nadie la tendrá.

La diferencia dentro de las dos pasiones es la distribución de derechos. Cuando los derechos son iguales, la emoción es envidia, cuando no son iguales, la emoción es celos.

Esta investigación es semántica, entendemos el patrón de reglas que permite utilizar estos conceptos. Es posible encontrar ejemplos de uno y otro en la vida cotidiana. Mis investigaciones en Estados Unidos hallaron una estrategia diferente en el caso de la vida sexual. Si la historia de Juan, Pablo y Conchita tiene lugar en Nueva York, Juan no se pone celoso, pero experimenta ira.

El sentido corporal y los comportamientos típicos de una emoción

En los episodios de la vida cotidiana, las acciones no se llevan a cabo tal y como se han descrito arriba. Si un hombre siente ira hacia su jefe lo más probable es que le queme el estómago y emita insultos sotto voce. Sin embargo, si la siente hacia su hijo se comportará con mucho ruido, gritará y lo golpeará.

Para entender estos fenómenos se necesita una divergencia dentro de la teoría lingüística de Austin. Desarrollando sus conceptos originales, hacemos ahora una distinción entre acciones, comportamientos que se intentan, y los actos sociales que se dan entre ese individuo y sus semejantes en virtud de sus acciones. Hay muchos tipos de acciones que conducen al mismo acto.

Cuando un ser humano despliega un comportamiento desde un "vocabulario" emocional, despliega una acción. Pero el acto que se logra para esta acción depende de las creencias de las persones implicadas. ¿Qué episodio existe y qué personas hay en el entorno social? Los actos que se configuran tienen que ver con las interpretaciones de los actores. Según esto, los sentidos y las acciones emocionales son elementos en una secuencia de acontecimientos, se dan como en una conversación. El modelo principal para entender los episodios sociales es precisamente éste: la conversación. Una disputa, un partido de tenis, el ataque a las Torres Gemelas de Nueva York..., todos tienen la estructura de una conversación, es decir, acciones que adquieren su papel como acto en el episodio gracias a sus sentidos. 
El principal interrogante para la investigación es: ¿qué secuencia de palabras tiene el mismo sentido?

\section{Conclusiones}

El ejemplo de las emociones esclarece, desde mi punto de vista, algunos detalles importantes del nuevo paradigma en la investigación psicosocial (Harré \& Parrott 1996). Una ventaja de todo esto es que presenta la oportunidad de analizar y entender la Psicología de las culturas ajenas. Cuando colocamos las posibilidades que ofrecen las investigaciones lingüísticas junto al análisis de las observaciones de la vida cotidiana de otra cultura, no tenemos dificultad para entender las reglas de comportamiento y las costumbres de esa cultura.

Los problemas que presenta, por ejemplo, la psicopatología son semejantes a los de la Psicología de las otras culturas. La posibilidad de entender la vida de los maniáticos depende del análisis de sus acciones como actos, eso sí, siempre desde el punto de vista de la mente del enfermo. El nuevo paradigma puede jugar en este campo el mismo papel que en el caso de las emociones (Gillett 1999).

\section{Referencias}

Gillett, G. (1999). The Mind and its Discontents. Oxford: Oxford University Press.

Harré, R. \& W. G. Parrott (1996). The Emotions. London: Sage.

Langenhove, L. van \& R. Harré (1999). Positioning Theory. Oxford: Blackwell.

\section{Referencia}

Harré,R. (2001). El papel de los estudios lingüísticos en la investigación psicosocial: el caso de las pasiones y los sentimientos. Atenea Digital, 1, 25-30. Accesible en:

http://seneca.uab.es/athenea/num1/harre.pdf 